\title{
FABRICATION AND TESTING OF REFRIGERATION USING ENGINE WASTE HEAT
}

\author{
S.Manojprabhakar ${ }^{1}$, R.C.Ravindranath ${ }^{2}$, R.V.Vinothkumar ${ }^{3}$, A.Selvakumar $^{4}$, K.Visagavel $^{5}$ \\ ${ }^{I}$ Student, Mechanical Engineering, Knowledge Institute of Technology, Tamilnadu, India \\ ${ }^{2}$ Student, Mechanical Engineering, Knowledge Institute of Technology, Tamilnadu, India \\ ${ }^{3}$ Student, Mechanical Engineering, Knowledge Institute of Technology, Tamilnadu, India \\ ${ }^{4}$ Asst.Professor, Mechanical Engineering, Knowledge Institute of Technology, Tamilnadu, India \\ ${ }^{5}$ Professor\&Head, Mechanical Engineering, Knowledge Institute of Technology, Tamilnadu, India
}

\begin{abstract}
The objective of project is to use vapour absorption system instead of vapour compression system. In this project is to reduce the fuel consumption by using of exhaust gas waste heat. This work presents an experimental study refrigeration system, using vapour absorption system. This system uses the exhaust waste heat of an internal combustion engine as energy source. The system was found to be applicable and ready to produce the required conditioning effect without any additional load to the engine. The proposed system decreases vehicle operating costs and environmental pollution caused by the heating system as well as causing a lower global warming.
\end{abstract}

Keywords: Waste heat, Refrigeration, Vapour absorption system and Internal Combustion Engine

\section{INTRODUCTION}

The term refrigeration in a broad sense is used for the process of removing heat (i.e. Cooling) from a substance. It is also includes the process of reducing and maintain the temperature of body below the general temperature of its surrounding. This project consists of an Electrolux refrigeration system using heat engine energy as input. The principle behind Electrolux refrigeration is that it uses three gases to accomplish its cooling effect namely ammonia (refrigerant), water (absorbent) and hydrogen. Ammonia is used as refrigerant as it is easily available, environmental friendly and can produce a better cooling effect. The refrigerator is invented in the car. The engine heat is supplied to the refrigerator and input heat is required at the generator where aqua ammonia is heated to get ammonia vapors. In this project, an experimental setup for Electrolux refrigeration is made using heat engine energy to supply input heat.. This can be achieved by vapor absorption system by using waste heat produced from engine.

\section{MAIN SECTION}

\subsection{Refrigeration}

Refrigeration is the process of removing heat from a body. The removed heat is moved to a place where it does not affect the working system. The main objective of refrigeration is to reduce heat to a lower temperature and maintaining it at that temperature. The term cooling refers generally to any natural or artificial process by which heat is dissipated.

\subsubsection{Coefficient of Performance (COP)}

The coefficient of performance, of a refrigeration system is the ratio of the heat removed from the cold reservoir to input work.

$$
\mathrm{COP}_{\text {cooling }}=\frac{\| \mathrm{QQ} \text { cold } \mid}{\Delta \mathrm{ww}}
$$

$\Delta Q$ cold $=$ is the heat moved from the cold reservoir (to the hot reservoir).

$\Delta \mathrm{w}=$ is the work consumed by the heat pump.

\subsubsection{Unit of Refrigeration}

Refrigerators are rated in $\mathrm{kJ} / \mathrm{s}$, or Btu/h of cooling. One ton of refrigeration Capacity can freeze one ton of water at $0{ }^{\circ} \mathrm{C}$ $\left(32^{\circ} \mathrm{F}\right)$ in 24 hours.

Based on that:

1 ton of refrigeration $=200 \mathrm{Btu} / \mathrm{min}=3.517 \mathrm{~kJ} / \mathrm{s}$

\subsubsection{Methods of Refrigeration}

Methods of refrigeration can be classified as

$$
\begin{aligned}
\text { i. } & \text { Cyclic } \\
\text { ii. } & \text { Non-Cyclic } \\
\text { iii. } & \text { Thermoelectric }
\end{aligned}
$$

Cyclic Refrigeration can be classified as:

1. Vapor cycle, and

2. Gas cycle 
Vapor cycle Refrigeration can further be classified as:

1. Vapor compression refrigeration

2. Vapor absorption refrigeration

\section{Vapor Absorption Cycle}

The working of absorption cycle is, the mixture of refrigerant and absorber i.e. strong solution is pumped to the generator using a small pump. The generator is the main unit of the whole refrigeration system. In generator heat is supplied to the strong solution. By using this heat refrigerant is separated from the mixture of strong solution and it forms vapours. The remaining weak solution flows back into the absorber.

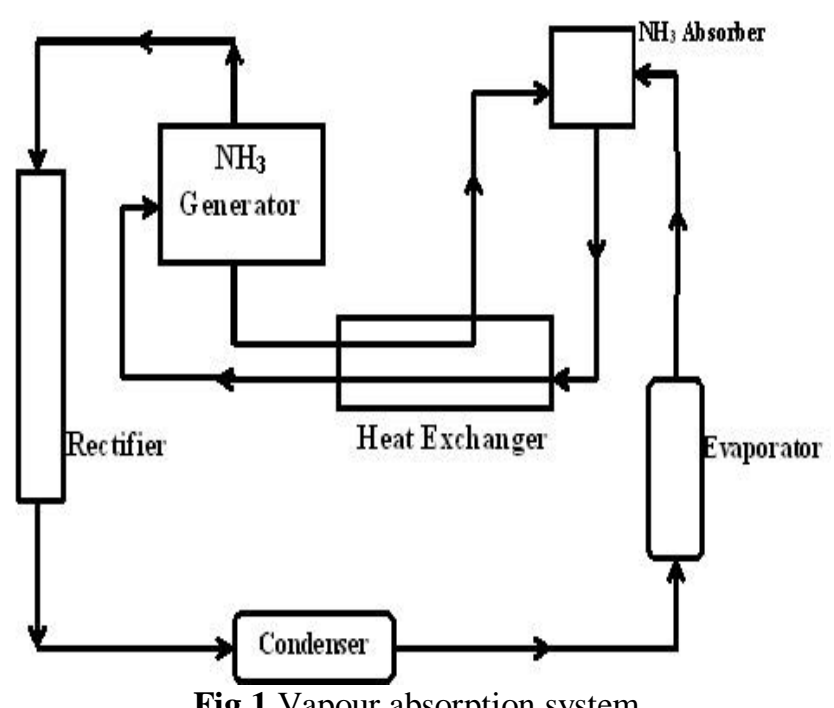

Fig 1 Vapour absorption system

The refrigerant passes through condenser here the heat of the vapour is removed and the temperature of refrigerant is brought to the room temperature. To bring the refrigerant temperature below room temperature it is passed through an expansion device. This refrigerant absorbs heat from the evaporator to produce required cooling effect. The hot refrigerant from the evaporator is mixed with weak solution from generator. They form the strong solution which is pumped to the generator for repeating the cycle.

\section{COMPONENTS}

The refrigeration system compresses of various components. They are as follows,
1. Condenser
2. Evaporator
3. Heat Exchanger
4. Refrigerant
5. Absorbent

\subsection{Condenser}

The condenser is used in the high pressure side of the system. The heat of refrigerant vapour is transferred to the walls of condenser and then to the cooling medium. In our work we used fin and tube condenser.

\subsubsection{Fin and Tube Condenser}

The Fin and Tube condenser is one in which the removal of heat is done by air. It consists of steel or copper tubing through which the refrigerant flows. The size of tube usually ranges from $6 \mathrm{~mm}$ to $18 \mathrm{~mm}$ outside diameter, depending upon of the size of the condenser. Generally copper tubes are used because of its excellent heat transfer ability. The fins are usually made from aluminium because of its light weight. The condensers with the single row of tubing provide the most efficient heat transfer. This is because the air temperature rises as it passes through each row of tubing.

\subsection{Evaporator}

The evaporator is used in the low pressure side of a refrigeration system. The evaporator absorbs heat from the body or surrounding which is to be cooled. This heat is transferred to the liquid refrigerant. At this place the liquid refrigerant becomes vapour. To make the heat absorption from the surrounding easy, the temperature of evaporator is always lees then the surrounding.

\subsubsection{Shell and Coil Evaporator (Cold Tank)}

The shell and coil evaporators are used to chill water. It is also known as dry expansion evaporators. The cooling coil may be spiral or double spiral. The shell sealed or open depends on the need.

\subsection{Heat Exchangers}

Heat exchangers transfer heat, mainly from one fluid to another fluid. They are also used in cooling applications like air conditioners, refrigerators. In parallel flow heat exchangers both the fluid moves in same direction. In cross flow heater exchanger, the fluids flow perpendicular to one another.

Types of Heat Exchangers

1. Shell and Tube Heat Exchanger

2. Plate Heat Exchanger

3. Regenerative Heat Exchanger

4. Adiabatic Wheel Heat Exchanger

In this project we used shell and tube heat exchanger.

\subsubsection{Shell and Tube Heat Exchanger}

The liquid flows through multiple tubes of shell and tube heat exchangers. There are two sets of tubes. One contains the liquid to be heated or cooled and the other contains liquid for performing heat exchange. The wall thickness and diameter should be made correct to make effective heat exchange.

\subsubsection{Heat Transfer Considerations}

The heat is transferred by convection in inner and outer side of inner tube. Heat transferred through conduction across the tube. The hot stream is in bigger diameter tube and energy flows between cold and hot streams. 


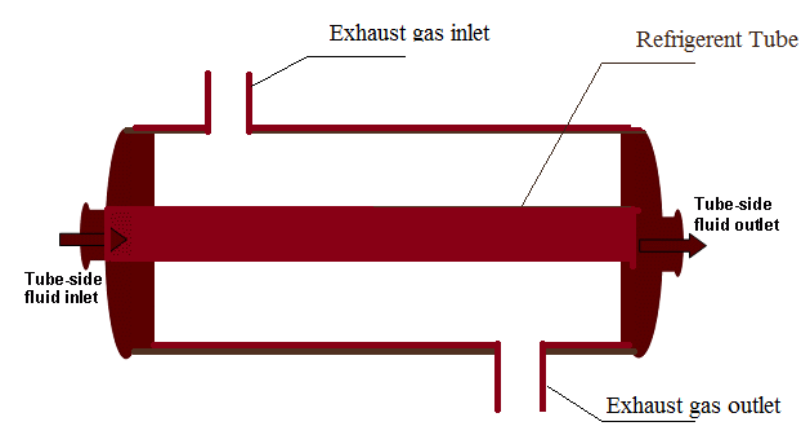

Fig 2 Tubular Heat Exchanger

$$
R=\frac{1}{h_{0} A_{0}}+\frac{\ln \left(\frac{r_{0}}{r_{i}}\right)}{2 \pi K l}+\frac{1}{h_{i} A_{i}}
$$

Overall heat transfer coefficient:

$$
U_{c}=\frac{1}{R A_{0}}
$$

Substituting the value of the thermal resistance $\mathrm{R}$ yields:

$$
\frac{1}{U_{c}}=\frac{1}{h_{0}}+\frac{r_{0} \ln \left(\frac{r_{0}}{r_{i}}\right)}{K}+\frac{A_{0}}{h_{i} A_{i}}
$$

\subsection{Refrigerants}

A refrigerant is a substance that absorbs heat from required body or substance. Example: water, ice, air. Etc.

\subsubsection{Selection of Refrigerant}

The thermodynamic, physical as well as safe working properties should be taken in to account before selecting a refrigerant for a particular purpose. There is no single best refrigerant which can be used for all refrigeration purposes.

The following properties must be taken in to account before selecting the refrigerant,

1. Working pressure range and pressure ratio

2. Corrosiveness and flame ability

3. Space limitation

4. Temperature required in the evaporator

The refrigerant used in our work is 'Ammonia'.

\subsubsection{Ammonia}

Ammonia is the only refrigerant from inorganic group which was used universally for many applications and still used to great extent at the present time. It possesses many properties required for an ideal refrigerant. It has wide applications because of its low volumetric displacement, low cost, low weight of liquid refrigerant per ton of refrigeration and high efficiency. Presently it is widely used in cold storages, ice manufacturing plants and skating rinks due to its low production and maintenance cost.

\section{Properties of Ammonia}

1. Its toxic, flammable, irritating and food destroying

2. Anhydrous ammonia has no effect on lubricating oil but in presents of moisture, ammonia forms an emulsion with oil that causes operating difficulties. The formed emulsion becomes effective when the percentage of water exceeds $0.01 \%$. It is not oil miscible therefore it will not dilute the oil in the crank case of the compressor.

3. It is highly volatile and becomes explosive when mixed with air and compressed therefore air leaks must be avoided in ammonia refrigeration systems.

4. Ammonia attacks on non-ferrous metals in the presents of water therefore copper and brass are never used with ammonia refrigeration system.

5. Ammonia can be used economically for $-70^{\circ} \mathrm{C}$ evaporator temperature and its application for further low temperature becomes highly uneconomical and difficult to maintain low vacuum required in the evaporator

The following table represents properties of ammonia.

Table 1 Properties of Ammonia

\begin{tabular}{|l|l|l|}
\hline 1 & Molecular weight & 17 \\
\hline 2 & Boiling point ${ }^{\circ} \mathrm{C}$ & -33 to $-35^{\circ} \mathrm{C}$ \\
\hline 3 & Freezing point ${ }^{\circ} \mathrm{C}$ & 77.7 \\
\hline 4 & Critical temperature ${ }^{\circ} \mathrm{C}$ & 133 \\
\hline 5 & Critical pressure bar & 112.8 \\
\hline & Specific heat $\mathrm{kJ} /(\mathrm{kg} \mathrm{K})$ & \\
& $0{ }^{\circ} \mathrm{C}$ & 2.0972 \\
6 & $100{ }^{\circ} \mathrm{C}$ & 2.2262 \\
& $200{ }^{\circ} \mathrm{C}$ & 2.1056 \\
\hline
\end{tabular}

Design Conditions for the Aqua Ammonia

\section{Refrigeration System:}

The values for the design of the Aqua Ammonia vapour absorption system are:

Specification of system:

Model: RB40

Net volume: 40 liters

Input voltage: $220-240 \mathrm{~V}, 50 \mathrm{~Hz}$

Power: 65W

Refrigerant: NH3

Mass of ammonia: $72 \mathrm{gm}$

Temperature of the evaporator, $\mathrm{Te}=8^{\circ} \mathrm{C}$

Condenser pressure, $\mathrm{Pc}=8$ bar

Evaporator pressure, $\mathrm{Pe}=1$ bar

Temperature of the Condenser, $\mathrm{Tc}=40^{\circ} \mathrm{C}$

Temperature of the Generator, $\mathrm{Tg}=95^{\circ} \mathrm{C}$

Heat obtained from engine waste heat: $165^{\circ} \mathrm{C}$

The corresponding pressure required can be noted from the refrigeration table of ammonia (R-717)

In this way, the condenser pressure is fixed at $\mathrm{Pc}=8 \mathrm{bar}$

Evaporator temperature $=8{ }^{\circ} \mathrm{C}$ required to be maintained in the evaporator chamber and evaporator pressure is kept 
equal to the atmospheric pressure ( 1 bar), to ensure design economy.

$\mathrm{h} 1=1620 \mathrm{KJ} / \mathrm{Kg}$ for Pc at 8 bar

$\mathrm{h} 2=\mathrm{h} 3=430 \mathrm{KJ} / \mathrm{Kg}$ for Pc at $8 \mathrm{bar}$

$\mathrm{h} 4=1570 \mathrm{KJ} / \mathrm{Kg}$ for Pe at $1 \mathrm{bar}$

\section{Cop of The System (Actual):}

The actual cop of the refrigerating unit can be calculated by using the equation,

$$
\begin{aligned}
\mathrm{Cop} & =(\mathrm{Te}(\mathrm{Tg}-\mathrm{Tc})) /(\mathrm{Tg}(\mathrm{Tc}-\mathrm{Te})) \\
& =(8(95-40)) /(95(40-8) \\
& =0.22
\end{aligned}
$$

\section{Ton of Refrigeration:}

For ammonia,

$$
\mathrm{Q} 1=\operatorname{mCp} \Delta \mathrm{T}=(0.072 \times 4.7 \times 8)
$$

[Since $\mathrm{Cp}$ of ammonia is $4.7 \mathrm{KJ} / \mathrm{KgK}$ ]

$$
\begin{aligned}
& =2.707 \mathrm{KJ} / \mathrm{min} \\
\mathrm{Q}_{2} & =\mathrm{m} \cdot \mathrm{hfg}=0.072 \times 1369
\end{aligned}
$$

[Since Latent heat of vaporization of ammonia is

$1369 \mathrm{KJ} / \mathrm{Kg}$ ]

$$
=98.568 \mathrm{KJ} / \mathrm{min}
$$

$$
\begin{aligned}
\mathrm{TR} & =(\mathrm{Q} 1+\mathrm{Q} 2) / 210 \\
& =101.275 / 210 \\
& =0.48 \text { ton of refrigeration }
\end{aligned}
$$

\section{Mass Flow Rate:}

Say the mass flow rate of ammonia in evaporator be $\mathrm{Mr}$

Therefore,

$$
\begin{aligned}
\mathrm{Mr} & =0.5 \mathrm{TR} /(\mathrm{h} 4-\mathrm{h} 3) \\
& =0.5(210) /(1570-430) \mathrm{KJ} / \mathrm{min} \\
& =0.092 \mathrm{KJ} / \mathrm{min}
\end{aligned}
$$

\section{Heat Absorbed From Aqua Ammonia Solution:}

The amount of heat of absorption is a function of the concentration of aqua and it is given by molier equation as

$$
\begin{aligned}
\text { Qa } & =802.5(1-\mathrm{xw})-928 \times w 2 \\
& =802.5(1-0.35)-928(0.35) 2 \\
& =407.945 \mathrm{KJ} / \mathrm{Kg}
\end{aligned}
$$

[Since concentration of water $\mathrm{xw}=0.35$ from the $\mathrm{H}-\mathrm{C}$ chart]
Using material balance equation,

$$
\begin{gathered}
(\mathrm{mw}+\mathrm{mr}) \mathrm{xs}=\mathrm{mrxr}+\mathrm{mwxw} \\
(\mathrm{mw}+0.092) 0.442=(0.09 \mathrm{x} 1)+(\mathrm{mwx} 0.35)
\end{gathered}
$$

Mass flow rate of water $(\mathrm{Mw})=0.56 \mathrm{Kg} / \mathrm{s}$

\section{Theoretical Cop of the System:}

$$
\begin{array}{ll}
\text { Cop } & =\text { Refrigerant effect } / \text { heat input } \\
\text { Cop } & =\mathrm{QE} / \mathrm{QG} \\
\mathrm{QG} & =\mathrm{mr} \mathrm{h} 1+\mathrm{mwh} 7-\mathrm{msh} 6
\end{array}
$$

[Since all the enthalpies are taken from the $\mathrm{H}-\mathrm{C}$ chart]

$$
\begin{aligned}
\text { QG } & =(0.09 \times 1620)+(0.56 \times 200)-(0) \\
& =257.8 \mathrm{KJ} / \mathrm{min} \\
\text { QE } \quad & =\operatorname{mr}(\mathrm{h} 4-\mathrm{h} 3) \\
& =0.092(1570-430) \\
& =102.6 \mathrm{KJ} / \mathrm{min}
\end{aligned}
$$

Now,

Theoretical COP $=(102.6) /(257.8)$

$$
=0.399
$$

\section{RESULTS:}

Designed operating conditions:

$\begin{array}{rll}\text { i. } & \text { Condenser pressure } & : 8 \mathrm{bar} \\ \text { ii. } & \text { Evaporator pressure } & : 1 \mathrm{bar} \\ \text { iii. } & \text { Heat input required at generator } & : 257.8 \mathrm{KJ} / \mathrm{min} \\ \text { iv. } & \text { Outlet temperature of exhaust gas } & : 165^{\circ} \mathrm{C} \\ \text { v. } & \text { Actual COP of the system } & : 0.15 \\ \text { vi. } & \text { Theoretical COP of the system } & : 0.399\end{array}$

\subsection{Result and Discussions}

\begin{tabular}{|l|l|l|l|l|}
\hline $\begin{array}{l}\text { S. } \\
\text { No. }\end{array}$ & $\begin{array}{l}\text { Time } \\
(\mathrm{min})\end{array}$ & $\begin{array}{l}\mathrm{Temp}\left({ }^{\circ} \mathrm{C}\right) \\
25 \% \\
\text { throttle } \\
\text { valve }\end{array}$ & $\begin{array}{l}\mathrm{Temp}\left({ }^{\circ} \mathrm{C}\right) \\
50 \% \\
\text { throttle } \\
\text { valve }\end{array}$ & $\begin{array}{l}\text { Temp }\left({ }^{\circ} \mathrm{C}\right) \\
75 \% \\
\text { throttle } \\
\text { valve }\end{array}$ \\
\hline 1 & 15 & 28 & 28 & 27 \\
\hline 2 & 30 & 28 & 27 & 25 \\
\hline 3 & 45 & 26 & 26 & 23 \\
\hline 4 & 60 & 25 & 25 & 20 \\
\hline 5 & 75 & 24 & 23 & 19 \\
\hline 6 & 90 & 22 & 21 & 18 \\
\hline 7 & 105 & 20 & 19 & 17 \\
\hline
\end{tabular}

\section{Mass of Water:}

$\mathrm{Xw}=$ mass of $\mathrm{NH} 3 /$ (mass of ammonia + mass of water)

$0.35=0.072 /(0.072+\mathrm{mw})$

$\mathrm{Mw}=0.133 \mathrm{Kg}$

the concentration of strong aqua solution becomes

$\begin{aligned} \mathrm{xs} & =\mathrm{xW}+\mathrm{mr} \\ & =0.35+0.092=0.442\end{aligned}$ 


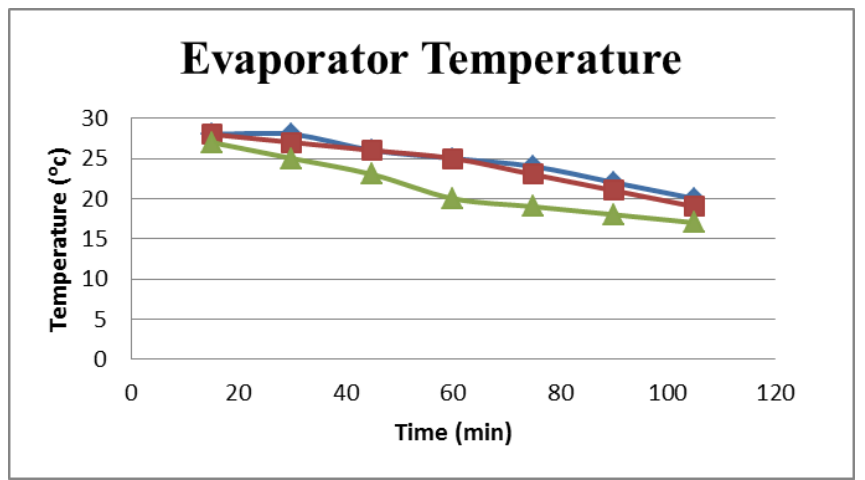

Fig 4 Time Variation of Evaporator Temperature

Figure 4 presents the evaporator temperature. From the above figure, it is observed that evaporator temperature decreases with time. It is depending on engine valve opening, the refrigeration system reaches the steady state condition and its interior starts cooling down, leading to the reduction of the evaporator average temperature. The temperature dropped faster inside the refrigerator as the throttle valve opening was wider. Attainment of the refrigerator steady state temperature was faster as the engine throttle valve was widened. Overall, the refrigeration average internal temperature took around 3-3.5 h to reach the steady state condition. The wider the valve opening, the lower the steady state average temperature attained inside the refrigerator. This temperature varied between $5^{\circ} \mathrm{C}$ and $13^{\circ} \mathrm{C}$ from a dedicated system. The absorption refrigeration system was shut down after approximately $3 \mathrm{~h}$, when the steady state temperature was attained.

Table 3 Time variation of Coefficient of Performance

\begin{tabular}{|l|l|}
\hline Exhaust temperature & COP \\
\hline 80 & 0.1 \\
\hline 92 & 0.15 \\
\hline 117 & 0.2 \\
\hline 125 & 0.25 \\
\hline 133 & 0.3 \\
\hline 148 & 0.35 \\
\hline 152 & 0.4 \\
\hline
\end{tabular}

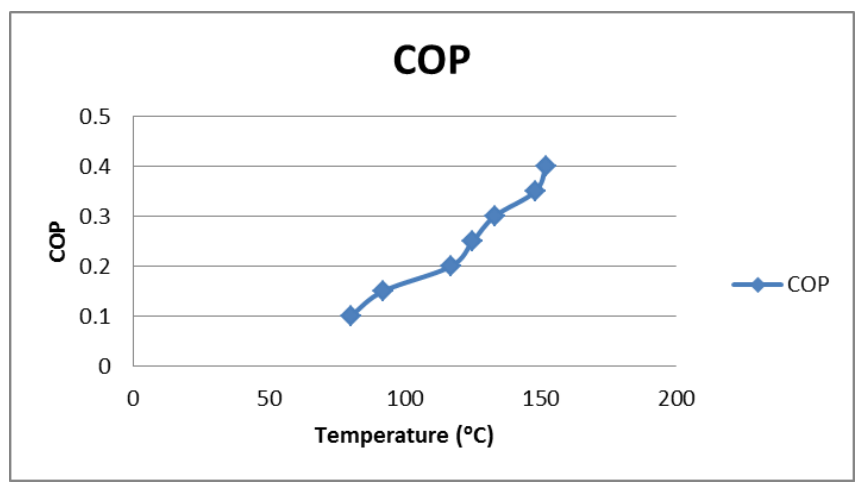

Fig 5 Time variation of Coefficient of Performance
Fig. 5 shows the time variation of the refrigerator coefficient of performance until system shut down after the steady state condition was attained. The maximum coefficient of performance was $4.9 \%$, for $25 \%$ open throttle. For all other valve opening, the peak coefficient of performance attained was even lower, of about $1.2-1.4 \%$.

\section{CONCLUSION}

The coefficient of performance of the system is low, that means that the system is expected to use a lot of energy with respect to the cooling it offers. But this is not a disadvantage in the case of our air-conditioner. This is because the energy we use is the engine waste heat energy which is available in automobile vehicles. Also, this safeguards the interest of the future generations who would be able to get air conditioning without use of electricity also. This is going to make the operational cost of the air conditioner very low. Moving parts are also not there in the system. Noise and vibrations are decreased to a minimum. Ammonia is a very cheap gas. This reduces the cost of the system. Waste heat is all what is needed for the system to operate. This project hence has a very bright future in the commercial market as well as in the industrial market.

\section{ACKNOWLEDGEMENTS}

This work was supported by Department of mechanical Engineering in Knowledge institute of technology. We are extremely grateful to thank our principal Dr.PSS.Srinivasan for providing all facilities to complete this project. The authors appreciate the support of Dr.K.Visagavel, Professor \& Head- Department of Mechanical Engineering and Mr.A.Selvakumar, Asst. Professor, Mech.

\section{REFERENCES}

[1]. Arora and Domkundwar, (2008), 'A Course in Refrigeration and Air-Conditioning',Dhanpa Rai \& Co.

[2]. André AleixoManzela (2010) 'Using Engine Exhaust Gas as Energy Source for an Absorption Refrigeration System', Applied Energy Vol. 87 pp. 1141-1148

[3]. Devotta, S., Wagmare, A.V., Sawant, N.N. and Domkundwar, B.M (2001) 'Alternatives to HFC-22 for air conditioners', Applied Thermal Engineering 21 pp. 703-715. [4]. Eames, I.W., (2000) 'Innovations in vapor-absorption cycles’, Appl. Energy 66, pp.251-266.

[5]. Jiangzhou et.al (2003) 'Locomotive Driver Cabin Adsorption Air-Conditioner', Renewable Energy Vol. 28 pp 1659-70.

[6]. Khaled, S. AlQdah (2011) 'Performance and Evaluation of Aqua Ammonia Auto Air Conditioner System Using Exhaust Waste Energy', Energy Procedia Vol.6 pp.467-476. [7]. Koehler ,J., Tegethoff, W.J, Westphalen, D. and Sonnekalb, M. (1997) 'Absorption refrigeration system for mobile applications utilizing exhaust gases', J Heat and Mass Transfer, Vol. 32, pp.333-340.

[8]. Meunier, P. (1993) 'Solid sorption: an alternative to CFCs, Heat Recovery Systems’ CHP 13 pp. 289-295. 
[9]. Robert, A. and Frosch (1980) 'Automotive absorption air conditioner utilizing solar and motor waste heat', United States Patent, Vol. 4, pp. 307,575.

[10]. Stoecker, W.F. (1998) 'Refrigeration and air conditioning', Mcgraw -hill book co.,Inc. pp. 179-83.

[11]. Talbi, M. et.al (2002) 'Energy Recovery from Diesel Engine Exhaust Gases for Performance Enhancement and Air Conditioning', Applied Thermal Engineering Vol. 22, pp. 693-702.

[12]. Wang, S. et.al (2008) 'A Car Air-Conditioning System Based on an Absorption Refrigeration Cycle Using Energy from Exhaust Gas of an Internal Combustion Engine', Journal of Energy in Southern Africa, Vol. 19 No 4.

[13]. Wang , S. (1997) 'Motor vehicle Air-conditioning utilizing the exhaust gas to power an absorption refrigeration cycle, MSc thesis, University of Cape Town South Africa.

[14]. Zhang, L.Z. and Wang,L. (1997) ' Performance estimation of an adsorption cooling system for automobile waste heat Recovery', Appl. Therm. Engg. Vol.17, pp.11271139

[15]. Bajpai, V.K. (2012) 'Design of Solar Powered Vapour Absorption System', Proceedings of the World Congress on Engineering (WCE), Vol. III. 